\title{
JUURNAL.RU
}

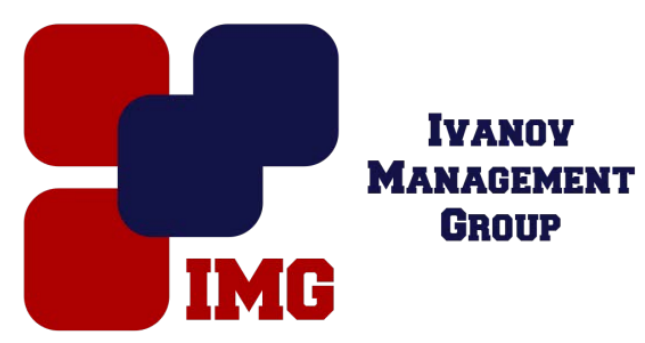

Сиразетдинова А.Ф.

Государственный Университет Управления Москва, Россия

doi: 10.18411/lj-31-10-2016-1-13

idsp 000001:lj-31-10-2016-1-13

\section{Анализ комплекса услугскладской логистики в России}

\section{Аннотация:}

В статье проанализирован комплекс услуг складской логистики, проблемы и перспективы, возникающие в процессе оказания услуг складской логистики, инноваций и новый технологии в складской логистике в России.

Ключевые слова: логистика, складскаялогистика,инновации,новые технологии,инновации,проблемы,перспективы.

Складская логистика является одним из звеньев логистической цепи, поэтому она рассматривается как составная часть всей системы логистики, которая и формирует организационные, технические и экономические требования к складской системе, устанавливает цели и критерии eе оптимального функционирования, диктует условия переработки груза. Необходимость в специально обустроенных местах для содержания запасов существует на всех стадиях движения материального потока, начиная от первичного источника сырья и кончая конечным потребителем[11-13]. Этим объясняется наличие большого количества разнообразных видов складов и большое внимание к проблемам, возникающим в складской логистике, к введению новых технологий и инновации, чтобы улучшать и развивать данную сферу деятельности.В последнее время в России отношение к логистике в корне изменилось. Сейчас отлаженный механизм транспортировки и складирования считается непременным условием успешной деятельности любого 
производственного или торгового предприятия. Любой компании, планирующей развитие на территории России, приходится принимать немало трудных и ответственных решений, связанных именно со складской логистикой. Вот поэтому тема статьи очень актуальна[3,8-10]

В современной России складская логистика имеет важнейшее значение, что в первую очередь связано с особенностью географии страны, огромными расстояниями между регионами, a также в значительном различии потребностей, ассортимента и предпочтениях потребителей в разных регионах.

Говоря о темпах развития логистики, следует отметить, что в России эта отрасль развивается не так стремительно, как в других

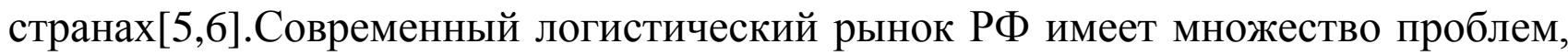
которые препятствуют нормальному развитию данной отрасли.

Из наиболее значимых следует отметить следующие:

- отсутствие квалифицированных кадров;

- слабая логистическая инфраструктура;

- использование устаревших технологий;

- непонимание руководством реальных проблемы собственного предприятия;

- отсутствие знаний в области управления складами.

Несмотря на все существующие проблемы, при определенных обстоятельствах ситуация может кардинально измениться в кратчайшие сроки. Обучение складской логистике квалифицированными специалистами позволит улучшить качество услуг и сделает их более востребованными[3,7].

В России постепенно отмечается увеличение степени автоматизации на складах, благодаря чему вероятность ошибки минимизируется, а скорость проведения работ повышается. Научно-технологические перспективы связаны с совершенствованием систем управления материальными ресурсами, в частности с автоматизированием контроля за внутрипроизводственными процессами. Эффективная работа по данным направлениям ведется, а значит, механизм развития логистики набирает обороты[6].

Логистические услуги в РФ становятся все более востребованными, что является главным стимулятором роста логистических компаний. С увеличением 
их численности потребителю услуг будет предоставлена возможность выбора, благодаря чему он сможет отдать предпочтение наиболее приемлемым условиям сотрудничества[6-8].

Технологическое улучшение складской инфраструктуры является одним из факторов повышения эффективности логистической цепочки в целом. За последнее десятилетие в нашей стране многие крупные логистические провайдеры добились заметных успехов в области внедрения современных технологий, хотя еще рано говорить о том, что перевод традиционной системы складского хранения на новую технологическую базу приобрел масштабный характер.Оборудование складских площадок по современным стандартам, автоматизация и роботизация всех процессов, комплексное компьютеризированное управление складскими операциями позволяют значительно сократить издержки и повысить надежность хранения, оптимизировать трудозатраты, обеспечить максимальный контроль над оборотом продукции[4-7]. Рассмотрим некоторые из новых технологий, которые эффективно внедряются и используются в складской логистике нашей страны.

RFID технология сегодня - одно из самых развивающихся направлений в области автоматической идентификации объектов. RFID технологии автоматизированные системы, использующие в своей работе метод автоматической идентификации объектов посредством радиоволн (RadioFrequencyIdentification, RFID).[4] В своем минимальном виде любая RFID технология как система предполагает наличие нескольких обязательных компонентов: RFID метка, представляющая собой наклейку с микрочипом и антенной внутри;RFID считыватель, представляющий собой защищенный компьютер с антенной. При активации системы считыватель посылает метке радиосигнал, в ответ на который метка передает считывателю свой идентификационный номер, в результате чего обеспечивается точная и быстрая радиоидентификация объекта, на который закрепляется метка[1]. В России данное направление появилось сравнительно недавно и в последнее время вызывает все больше интереса со стороны ИТ-компаний, государственных заказчиков, коммерческих предприятий и профессиональных сообществ. Так, в Рунете появились новые специализированные порталы (RFIDEXPERT, ID Expert), государство (РОСНАНО) создает проектные компании и обсуждает 
вопросы стандартизации (ГКРЧ), на рынок выходит все больше ИТ-компаний, которые заинтересованы в развитии и интеграции проектов на базе RFID технологии. Интерес к технологии выражается и в чисто экономических показателях. Так, согласно оценке экспертов, совокупный среднегодовой темп роста RFI D рынка в России в период с 2008 по 2010 год превысил 19\%[1,4,14].

Голосовую технологию в процессах комплектования продукции (Pick-byVoice) в России начали внедрять сравнительно недавно, не более десяти лет назад, но за это время она уже прекрасно зарекомендовала себя в отраслях, связанных с транспортировкой и хранением таких товаров, как швейные изделия, напитки, охлажденные и замороженные продукты, расфасованные товары, товары для общественного питания и бакалейные, медикофармацевтические и товары, поставляемые сторонним фирмам. Применение такой технологии на крупных складах предоставляет огромные преимущества, а появление надежной аппаратуры в сочетании с совершенным программным обеспечением являются существенными составляющими, определившими успешность новой технологии. Голосовые системы управления складами значительно изменили на всех уровнях характер работы применивших их компаний. По сообщениям зарубежной печати, благодаря использованию этой технологии ряду фирм удалось улучшить важнейшие показатели своей деятельности, такие как производительность (до 35\%) и точность выполнения заказов (доведена до 99,99\%), а также уменьшить количество больничных листов и время обучения персонала (на 50\%), текучесть кадров. Несмотря на новизну технологии, в настоящее время ее уже применяет примерно 500 компаний, а это означает, что более 100 тысяч операторов на складах каждый день пользуются голосовой аппаратурой. В нашей стране она пока не применяется, но обязательно будет, скорее всего, уже в самом ближайшем будущем.

Технология pick-by-voice или voicepicking (подбор товара с помощью голосовых команд) применяется в европейских странах и в США уже около 20 лет[14]. В нашей стране до недавнего времени подбор осуществлялся по бумажному носителю и радиочастотному терминалу, однако в последние годы логистические компании в России начинают тестировать и активно внедрять эту разработку.Технология позволяет работнику склада поддерживать 
непосредственный голосовой контакт с WMS-системой в процессе выполнения заказов[4]. Аппаратура представляет собой беспроводной компьютер, который «общается» с WMS-системой при помощи радиосвязи, и гарнитуру, посредством которой оператор слышит задания и может сообщать об их выполнении. Главный компьютер посылает указания на компьютер работника склада, например, данные о количестве товаров в заказе и месте их расположения. Выполнив задание по подбору, исполнитель подтверждает его завершение голосовой командой, после чего главный компьютер высылает данные следующего заказа. Основным преимуществом технологии голосового отбора являются свободные руки сборщика, которому не нужно держать в руках терминал или бумажный носитель[2]. Технология VoicePicking позволяет значительно повысить точность и оперативность выполнения заказов, что благоприятно сказывается на общей производительности работы склада. Поскольку при подборе заказа по технологии Pick-by-Voice отсутствуют многошаговые и сложные операции, время подготовки персонала заметно сокращается[2,4,14]. 


\section{Литература}

1. http://www.tendo.ru/rfid/96.html

2. http://www.wikipro.ru/index.php/Pick-byvoice_технология_третьего_тысячелетия

3. http://hiterbober.ru/business-terms/chto-takoe-skladskaya-logistika.html

4. http://issa.ru/news/2013/12/05/news_2978.html

5. https://cargolink.ru/ls/blog/536.html

6. http://moluch.ru/archive/117/28947/(Осипов B. А. Проблемы развития логистики в России // Молодой ученый. — 2016. — №13.1. — С. 75-77.)

7. http://www.logists.by/library/view/Pick-by-voice

8. Логистика и управление цепями поставок. Теория и практика. Основы логистики. Аникин Б.А.; Родкина Т.А.; Волочиенко В.А.; Заичкин Н.И.; Межевов А.Д.; Федоров Л.С.; Вайн В.М.; Воронов В.И.; Водянова В.В.; Гапонова М.А.; Ермаков И.А.; Ефимова В.В.; Кравченко М.В.; Серова С.Ю.; Серышев Р.В.; Филиппов Е.Е.; Пузанова И.А.; Учирова М.Ю.; Рудая И.Л. Учебное пособие / Москва, 2014.

9. Логистика: тренинг и практикум. Аникин Б.А., Вайн В.М., Водянова В.В., Воронов В.И., Гапонова М.А., Ермаков И.А., Ефимова В.В., Заичкин Н.И., Кравченко М.В., Пузанова И.А., Родкина Т.А., Серова С.Ю., Серышев Р.В., Федоров Л.С. Учебное пособие / Москва, 2014.

10. Аникин Б. А., Ермаков И.А, Белова С. Научная школа «Логистика» ГУУ. Управление. 2015. Т.3.№ 2 С. 5-15.

11. Воронов В.И., Воронов А.В. Международные товаропроводящие сети. Маркетинг. 2013. № 6 (133). С. 20-28.

12. Воронов В.И. Международная логистика. Вестник университета (Государственный университет управления). 2004. Т.700.c.700.

13. Воронов В.И., Воронов А.В. Основные элементы эволюции элементов цепей поставок в международной логистике ЛОГИСТИКА. Проблемы и решения. Международный научно-практический Украинский Журнал. 2013 №, 2. Украина. Харьков. 
14. Воронов В.И., Кривоносов Н.А. Савостьянок Г.Н., Кожанова В.В Инновационные технологии в логистике. Научно-аналитический журнал: «Инновации и инвестиции» № 4, 2015- стр.2-4 